\title{
COMO É CRIADO O DISCURSO PEDAGÓGICO DOS MUSEUS? FATORES DE INFLUÊNCIA E LIMITES PARA A EDUCAÇÃO MUSEAL
}

\author{
Luciana Conrado Martins* \\ Universidade de São Paulo
}

\section{RESUMO:}

Objetiva compreender a lógica de constituição do discurso pedagógico dos museus. Optou-se pela teoria de Basil Bersntein, buscando entender quais os fatores de influência e os limites que atuam nessa definição, bem como o que traz para a prática instrucional dessas instituições. Utilizou-se abordagem qualitativa, comparando duas tipologias de museus - de artes plásticas e de ciências humanas. Conclui-se a existência de uma prática instrucional indireta nos museus, pautada por um viés dialógico entre educadores e públicos. Os educadores encontram limites para a proposição de suas práticas, mas também possuem autonomia, principalmente sobre as metodologias empregadas nas ações educacionais.

\section{PALAVRAS-CHAVES:}

educação, museus, discurso pedagógico, prática instrucional
How is the pedagogical discourse of museums created? Influencing factors and limits for museum education

\begin{abstract}
:
Aims to understand the logic of the constitution of pedagogic discourse of museums. The option was used the theory of Basil Bernstein, trying to understand what factors of influence and limits work in this setting, as well as what brings to the instructional practice of these institutions. We used the qualitative methodological background, comparing two types of museums - a fine arts museum and a human sciences museum. We conclude the existence of an indirect instructional practice in museums, guided by a dialogical bias among educators and public. Educators have limitations to propose their practices, but they also have autonomy, especially on the methodologies employed in educational activities.
\end{abstract}

\section{KEY-WORDS:}

education, museum, pedagogic discourse, instructional practice

\footnotetext{
* Doutora em Educação pela Universidade de São Paulo. Sócia-diretora da empresa Percebe, pesquisa, consultoria e treinamento educacional, na qual desenvolve projetos educacionais para museus, exposições e formação de educadores e professores (www.percebeeduca.com.br).
} 


\section{Introdução}

Os museus têm se consolidado na contemporaneidade não só como espaços educacionais, como suas práticas pedagógicas têm sido alvo de inúmeros estudos relacionados aos diversos aspectos que caracterizam essa tipologia educacional. Estudos sobre aprendizagem (Falk e Dierking, 2000, 2002; Falk e Storksdieck, 2005; Hein, 1998), a relação dos museus com outras agências educacionais, como as escolas (Larouche e Allard, 1997; Van-Praët e Poucet, 1992), e sobre as relações entre museus e sociedade (Falcão e Gilbert, 2005; Hooper-Greenhill, 1994) são alguns dos temas que têm repercutido entre os interessados nesse campo de estudos específico.

Todos esses estudos contribuem para aquele que é tema de interesse central deste artigo: a constituição da especificidade da educação em museus. O que se constata é que, apesar de um notório fortalecimento da área, existem questionamentos não respondidos sobre a especificidade do funcionamento e das características da educação museal. Os museus, em sua imensa variedade de tipologias de acervos e conformações institucionais comportam um sem fim de práticas educativas voltadas para públicos e objetivos diversos. $O$ que, então, caracteriza, diferencia e singulariza a educação praticada em um universo tão multifacetado? É possível afirmar a existência de uma singularidade educacional denominada educação em museus? Frente a outras práticas educacionais, como a educação escolar, essa singularidade pode ser evidenciada e caracterizada?

Um dos aspectos que se mostra importante para a caracterização da educação existente nos museus é a compreensão dos processos que levam a delimitação dos objetivos, conteúdos e métodos da educação museal. Considera-se que a exemplo de outras instituições educacionais - como as escolares - os museus produzem discursos pedagógicos próprios, passíveis de serem transmitidos aos seus públicos frequentadores. Entender a lógica de constituição desse discurso enquanto prática social, quais os seus agentes e quais os seus limites, é o foco principal deste artigo. Para a estruturação da análise aqui pretendida utilizou-se a teorização proposta pelo sociólogo da educação Basil Bersntein, a partir de seu conceito de discurso pedagógico.

A utilização de um sociólogo da educação para o estudo da especificidade da educação em museus se justifica pela pouca presença, apontada pela bibliografia pertinente (Hooper-Greenhill, 1994; Mcmanus, 2000), de trabalhos que se debruçam sobre os processos sociais por trás da conformação das ações educacionais museais. Partindo-se da compreensão de que a educação é antes um processo do que um produto, coloca-se premente a necessidade de investigações de caráter sociológico que abordem a elaboração dos processos comunicacionais e educacionais dos museus, principalmente sobre o comportamento das equipes envolvidas e sua influência na prática desenvolvida com os públicos.

\section{Metodologia}

Ao buscar compreender a constituição da educação em museus a perspectiva conceitual escolhida funda-se, basicamente, no desvelar dos processos sociais que caracterizam a educação praticada nesses locais. Nesse sentido, essa pesquisa é tributária de estudos que, nesse campo específico, optaram pela abordagem qualitativa de pesquisa (Garcia, 2006; Marandino, 200I; Martins, 2006; Navas, 2008, entre outros). Tendo como objetivo a compreensão da especificidade da constituição da educação praticada nos museus, o presente trabalho centra-se na investigação dos processos sociais que constituem essa educação, tendo 
como foco, primordialmente, a visão dos profissionais envolvidos na concepção e realização das prática educacionais dos museus.

Os referenciais da pesquisa qualitativa em educação (Bogdan e Biklen, 1994; Cohen et al., 2007) foram utilizados como subsídio metodológico para a coleta de dados e estruturação do estudo, bem como para a identificação dos agentes que participam desses processos. A abordagem qualitativa é particularmente eficaz neste caso, na medida em que permite, de acordo com Bogdan e Biklen (1994) a compreensão dos processos educacionais, mais do que seu produtos finais. De acordo com esses autores a pesquisa qualitativa em educação permite a ênfase nos significados dados aos seus atos pelos sujeitos envolvidos nas situações estudadas. É justamente a partir da fala dos educadores de museus e de suas concepções sobre sua prática profissional que são realizadas as análises aqui empreendidas.

Para este trabalho optou-se por um estudo comparativo entre duas tipologias institucionais de museus - um museu de artes plásticas, a Pinacoteca do Estado de São Paulo, e um museu de ciências humanas, o Museu de Arqueologia e Etnologia da Universidade de São Paulo. Para a seleção das instituições investigadas foram levados em conta os seguintes critérios:

1) Existência de ação educacional dentro do museu - considerou-se como critério definidor dessa existência a presença institucional de um departamento/seção/grupo de pessoas responsáveis pela educação, desenvolvendo atividades contínuas para o público de visitantes por cinco anos ou mais. Após uma seleção inicial de museus, foi procedida à seleção final com base no critério seguinte.

2) Existência de investigação acadêmica em educação museal feita pela equipe - a partir da listagem inicial, foi realizada uma investigação direcionada a partir de nomes de autores e/ou instituições em periódicos e anais de congresso das áreas de Museologia, educação em museus e áreas de educação específicas. Esse levantamento foi complementado com a busca de outras publicações de cada autorı.

Ambas instituições selecionadas são referenciais para a área de educação em museus nacional. Seus educadores são produtores de conhecimento sobre o tema da educação em museus, com participação nos fóruns e associações profissionais específicas, além dos congressos da área. Nesse sentido, esses museus são bastante diferenciados em termos qualitativos de outras instituições museais nacionais. $A$ validade da investigação realizada reside, justamente, na percepção do funcionamento da ação educacional naquelas instituições nas quais esse tipo de ação acontece com excelência. $O$ estudo dos museus apontados configura-se, dessa forma, como "casos exemplares", tanto pelo nível de estruturação temporal e institucional de suas ações, quanto pela importância de suas práticas em termos de produção acadêmica no campo educacional museal.

Os dados para este artigo foram coletados ao longo dos anos de 2009 e 2010, por meio de entrevistas semi-estruturadas com os educadores dos museus estudados. Foram entrevistados dois profissionais em cada um dos museus. Para a escolha dos profissionais entrevistados priorizou-se aqueles diretamente envolvidos na concepção das ações educativas da instituição. Foram entrevistados, nos dois museus, o chefe/coordenador da seção/departamento de educação e mais um profissional a ele subordinado, mas diretamente envolvido na concepção das ações.

I Para maiores detalhes da análise bibliográfica empreendida ver Martins (20I I). 
Além das entrevistas, foram realizadas análises documentais e observações. A análise documental compreendeu o já citado levantamento da produção acadêmica dos setores educativos investigados. Foram também analisados diversos documentos institucionais, tanto produzidos pelo próprio setor educativo como documentos da direção da instituição com relação e/ou relevância direta para a ação educacional. Sobre as observações, elas priorizaram as práticas educacionais dos museus estudados foram realizadas quando necessário ao andamento das pesquisas.

É importante ressaltar que essa coleta de dados foi realizada no âmbito do desenvolvimento da tese de doutorado da autora. Dessa forma, nem todos os dados aqui citados serão evidenciados ao longo do presente artigo no qual, devido ao recorte estabelecido, foi priorizada a apresentação dos dados oriundos das entrevistas com os educadores dos museus estudados. Considerou-se importante a menção à metodologia, na medida em que as conclusões aqui apresentadas também são tributárias do todo da pesquisa.

\section{O discurso pedagógico e a definição da prática instrucional museal}

O discurso pedagógico, conforme proposto por Bernstein (1996, 1998), é entendido como um princípio que regula a apropriação de outros discursos a fim de submetê-los ao processo de transmissão e aquisição seletivas. Ao sair de seu local de criação original para o contexto pedagógico o discurso específico de uma área de conhecimento - das ciências humanas ou das artes, por exemplo - é transformado em um processo denominado por Bernstein de recontextualização.

Essa transformação acontece justamente no espaço vazio deixado pelo discurso ao ser deslocado: esse espaço dá margem para uma atuação ideológica dos sujeitos que transformam o discurso original em um novo discurso. "O discurso pedagógico está constituído por um princípio recontextualizador que se apropria, recoloca, recentra e relaciona seletivamente outros discursos para estabelecer sua própria ordem" (Bernstein, 1998: 63, tradução nossa). Dessa forma, o princípio de recontextualização regula a transformação do texto específico de uma área em um conteúdo próprio para uma idade determinada.

Para esclarecer melhor o funcionamento do princípio recontextualizador Bernstein utiliza um exemplo vindo da Física. Existe a Física enquanto campo de produção de conhecimento científico e existe a Física enquanto disciplina escolar. A disciplina Física já é, ela própria, um discurso recontextualizado, pois é o resultado de princípios de recontextualização que selecionaram conhecimentos no campo da produção original, que foram refocados para serem utilizados no campo de reprodução do discurso (no caso de Bernstein, a escola de ensino médio). Essa recontextualização é realizada levando-se em consideração a relação da Física com outras disciplinas (chamados de princípios de classificação) e o sequenciamento e ritmo escolares (chamados de princípios de enquadramento). Ou seja, a Física é submetida à processos de seleção e refocagem que não são relacionados com sua lógica de produção original e que obedecem somente à lógica de reprodução do discurso pedagógico, a lógica da recontextualização intrínseca ao discurso pedagógico.

A atividade principal do processo de recontextualização é, portanto, a de proporcionar o que e o como do discurso pedagógico. $O$ que refere-se às recontextualizações realizadas a partir dos campos de conhecimentos específicos, como a História, as Artes ou as Ciências Naturais. Já o como refere-se às teorias 
da instrução e da aprendizagem, usualmente estabelecidas pela Psicologia e pela Pedagogia. Dessa forma, na atuação do campo recontextualizador, os discursos vindos de campos de produção do conhecimento distintos são agrupados a partir de uma lógica diferenciada, a lógica educacional.

Outro aspecto importante da conformação do discurso pedagógico é dado pelos denominados princípios de avaliação2, que regulam a prática pedagógica, organizando o processo de recontextualização do conhecimento para sua transmissão. Esse processo é condicionado pelas regras de recontextualização e é constituído a partir das realizações do discurso instrucional específico (DIE) e do discurso regulador específico (DRE).

A estrutura teórica proposta por Bernstein permite, portanto, a compreensão de dois níveis distintos dentro do processo de conformação do discurso pedagógico. Um primeiro voltado à enunciação e recontextualização do texto pedagógico e um segundo voltado à prática pedagógica propriamente dita. $\mathrm{O}$ interesse do presente artigo está voltado justamente para a passagem da recontextualização para a prática pedagógica, ou seja, para o processo de definição dos textos que regulam essa prática.

Dada a enormidade das possibilidades de análise possíveis a partir das teorias de Basil Bernstein, optou-se em neste artigo, em focar um aspecto da conformação do discurso pedagógico museal: o discurso instrucional específico (DIE). Segundo Bernstein, o DIE comporta dois blocos de teorias instrucionais: um primeiro que regula aquilo que será transmitido - o conteúdo específico recontextualizado - e um segundo que regula como será a transmissão e aquisição desse conteúdo - as teorias de transmissão e aquisição, também recontextualizadas. Esse discurso posiciona os sujeitos - adquirentes e transmissores - em relação às essas práticas pedagógicas e aos seus significados, conformado as relações sociais entre eles.

Essas relações sociais, por sua vez, são reguladas por dois tipos de regras: as regras de hierarquia - relativas às relações de poder entre adquirentes e transmissores - e as regras discursivas - relativas à seleção, sequência, ritmagem e critérios de avaliação do processo de transmissão-aquisição. São as variações nessas regras que determinam as modalidades de prática pedagógica ou modalidades de instrução. Para melhor compreensão do conceito, Domingos e outras fornecem três modalidades de práticas pedagógicas instrucionais possíveis, resultantes das modalidades de DIE: a prática instrucional didática - cujo processo instrucional é altamente regulado pelo transmissor, de acordo com a lógica das teorias behavioristas -; a prática instrucional indireta - cujo processo é centrado no adquirente, dentro de uma lógica que privilegia o conhecimento prévio e os ritmos individuais -; e uma terceira modalidade que conjuga uma teoria de aquisição indireta com uma teoria de transmissão direta, redunda em uma pedagogia denominada pelas autoras como "mascarada", na qual "a única mudança nas relações de poder da instrução é o apelo retórico à cooperação, continuando a aquisição a ser regulada por regras discursivas explícitas" (Domingos et al., 1986, p. 307). As possibilidades de arranjos entre essas relações permite distintas configurações pedagógicas com variados graus de controle e autonomia dos sujeitos envolvidos.

Pretende-se, a partir dos estudos de caso mencionados, entender quais as condicionantes e os limites para a definição do discurso instrucional dos

2 Vale notar que os princípios de avaliação, conforme compreendidos por Bernstein, são parte do funcionamento do dispositivo pedagógico e não têm relação com a avaliação de processos, práticas e sujeitos da educação. 
museus e quais os impactos que essa definição traz para a prática instrucional dessas instituições.

\section{O discurso instrucional e as modalidades de práticas pedagógicas dos museus}

Os museus aqui estudados possuem, como dito anteriormente, serviços educativos consolidados e suas ações educativas são estabelecidas por educadores que muitas vezes possuem pós-graduação em temas relacionados à educação museal. $O$ que se percebe, a partir desses dados, é a configuração de um campo no qual os próprios educadores dos museus estabelecem seus questionamentos e temas de investigação, buscando nos seus trabalhos acadêmicos não só a referência para a prática, mas para a própria formação (Martins, 201 I; Seibel-Machado, 2009). Soma-se a essa constatação a presença de grupos de pesquisa, periódicos e associações nacionais e internacionais de educadores de museus voltadas à constituição e consolidação de um campo de reflexão e análise sobre a prática educacional museal, além de uma plataforma de trocas de conhecimentos específicos para a atuação profissional.

Configura-se, a partir do exposto, uma situação em que os educadores refletem e geram um conhecimento específico sobre sua prática educacional, utilizando-o para referendar suas escolhas. Ou seja, os educadores são os responsáveis pela geração do discurso original sobre a educação em museus, pois são eles quem, em grande medida, produzem o conhecimento específico dessa área, atuando como agentes recontextualizadores do discurso pedagógico dos museus3. As regras de recontextualização, no âmbito da educação em museus, colocam nos agentes museais um grande poder decisório sobre o como e o que serão reproduzidos para os públicos dessas instituições, em termos de discurso pedagógico.

$\mathrm{Na}$ acepção de Bernstein, o discurso pedagógico atua como um princípio que regula a transformação de outros discursos dentro do processo de transmissão-aquisição educacionais. Nesse sentido, o discurso instrucional específico (DIE) define as modalidades pedagógicas de reprodução. Isso quer dizer que é o DIE que estabelece o que é transmitido e como se dá o processo de transmissão e aquisição.Atuam na composição do discurso instrucional o conhecimento específico disciplinar (das competências e destrezas) e as teorias de instrução.

A partir da fala dos educadores de museus estudados é possível perceber quais são os limites que atuam na composição dos discursos instrucionais institucionais. Um primeiro aspecto analisado diz respeito aos limites estabelecidos a partir dos objetivos da ação educativa. No Museu de Arqueologia e Etnologia da USP (MAE-USP) o foco da ação educativa está voltado à discussão diversidade cultural.

Acho que o MAE tem um grande papel, dada a natureza do seu acervo, que é apresentar e discutir a questão da diversidade cultural e dar conceitos de tolerância.Acho que o nosso acervo provoca isso e acho que o Educativo, o tempo inteiro, quer trabalhar com essa grande questão junto ao público. Então todas as nossas atividades, aí variam com a estratégia, o formato, elas têm essa grande ambição que é apresentar a questão da diversidade cultural e discutir, problematizar isso, uma vez que o nosso país, acho que a gente sofre com isso, está na nossa cara

3 É importante salientar que nem todos os agentes recontextualizadores do discurso pedagógico dos museus são ligados à prática dos museus. Para maiores detalhes ver MARTINS (20I I). 
o tempo inteiro, mas a visão crítica sobre isso é muito pequena. (MAE-USP - educador 2).

Eu entendo que a nossa perspectiva educacional é na construção de um cidadão globalizado, de fato preparado para lidar com a globalização. É só você entendendo que existe uma diversidade, e que a diferença, ela não só existe mas ela é um valor, ela não é algo depreciativo, e por outro lado que é fundamental a construção de uma tolerância, por que você só vai respeitar, você só vai encarar de vez a diversidade cultural e enfrentar a diferença se você fizer um exercício de tolerância. Entender, ou buscar os motivos do outro ser da forma como ele é.Ao mesmo tempo você se entender a forma como você é na relação com o outro. (MAE-USP - educador I).

O objetivo da ação educacional desse Museu está estreitamente relacionado com o discurso expresso na exposição de longa duração do Museu. Intitulada "Formas de Humanidade", a exposição tem justamente a pretensão de expor os modos de vida e as expressões culturais de diferentes grupos humanos, a partir de um olhar não etnocêntrico4. Esse discurso é construído a partir das pesquisas desenvolvidas em Arqueologia, Etnologia e Museologia.

Acho que a pesquisa também tem um grande interesse de entender o nosso país de uma maneira mais múltipla. Pesquisa em Arqueologia e Etnologia, na museologia também, quando faz propostas de comunicação, também tem como grande propósito dos seus projetos evidenciar isso. (MAE-USP - educador 2).

Estabelece-se, portanto, uma estreita relação entre o discurso produzido pela pesquisa das áreas científicas do Museu e o discurso da educação no MAE-USP.

Que é uma exposição que procura dar conta da diversidade de pesquisas do Museu e das coleções também, ela é bastante abrangente nesse sentido, acho que é uma grande vitrine mesmo do que é o MAE. (MAE-USP - educador 2).

Essa relação entre o conhecimento específico e o conhecimento educacional, entretanto, não se fez sem conflitos.Além de um surgimento conturbado - fruto da fusão de quatro diferentes acervos institucionais de Arqueologia e Etnologia pertencentes à Universidade de São Paul05, bem como de suas equipes - o MAE-USP é um museu universitário, com complexas tensões entre as áreas científicas e educacional. A partir da fala dos educadores, percebe-se que no MAE-USP a educação ocupa um espaço peculiar, condicionado pelo fato dessa ser uma instituição universitária.

Acho que sempre há uma briga, se o conhecimento tem o mesmo peso.

[...] Pensando o MAE tendo Arqueologia, Etnologia e Museologia, acho

4 A exposição "Formas de Humanidade" esteve aberta ao público de 1995 a 2010.0 MAE-USP está em reforma e a nova exposição de longa duração ainda não tem data de abertura prevista.

5 O Museu de Arqueologia e Etnologia da USP tem sua origem na fusão, em 1989, do Instituto de Pré-História (IPH), do antigo Museu de Arqueologia e Etnologia (MAE), do acervo Plínio Ayrosa, do Departamento de Antropologia da Faculdade de Filosofia, Letras e Ciências Humanas e do acervo arqueológico e etnográfico do Museu Paulista. Essa fusão representou não só a união física dos objetos dos acervos, como também a junção das equipes das diferentes instituições e distintos métodos de trabalho. Para maiores detalhes sobre o processo de fusão ver Bruno (1995), Carneiro (2009) e Martins (201 I). 
que nem a própria Museologia é visto como uma área da pesquisa. Educação aqui é visto como uma área técnica, então é bem só o perfil da atuação direta com o público. (MAE-USP - educador 2).

$\mathrm{Na}$ visão dos educadores do MAE-USP a área educativa não possui, entre os pesquisadores da instituição, o mesmo status da área que gera conhecimento específico sobre Arqueologia e Etnologia6. Essa situação, recorrente nos museus universitários cujos acervos são alvo de pesquisa acadêmica sistemática, não foi construída da noite para o dia, estando relacionada ao posicionamento dos sujeitos e de suas práticas profissionais ao longo da trajetória histórica institucional (Marandino, 200 I; Martins, 2006). Colabora nesse contexto o fato de que, numericamente, a Divisão de Difusão Cultural do MAE-USP, conta com menos docentes e técnicos do que a Divisão Científica7.

Então no fundo a gente não é encarado como pesquisador. Não estou nem falando docente. Porque a gente faz pesquisa também, o nosso trabalho produz conhecimento. [...] Não estou dizendo que eu estou fazendo Arqueologia, mas o que a pesquisa em Educação faz, também pode contribuir para a Arqueologia. Mas esse diálogo não acontece. (MAE-USP - educador 2).

A questão que se coloca a partir dessa comparação é a de que uma área relativamente recente em termos de produção acadêmica - $a$ área de educação em museus - não tem a mesma força que uma área de conhecimento consolidada - seja a Zoologia, seja a Arqueologia ou a Etnologia. Alia-se a isso o fato de que, dentro da estrutura hierárquica universitária, na qual o MAE-USP se encontra inserido, os educadores não têm equivalência em termos de cargos, salários e poder decisório.

Por outro lado, é possível perceber que a proposição das atividades educativas institucionais é realizada com um grande grau de autonomia por parte dos educadores.

A idéia mesmo é de pensar coisas novas. $E$ essas coisas novas vêm por demandas que a gente percebe, necessidades do público, entradas interessantes, que a gente fala: "Ah, se tivesse um material. Que seria muito legal se a gente fizesse essa atividade desse jeito", e aí começar a estruturar essa atividade e ver o que é necessário para que ela aconteça. [...] geralmente essas propostas elas surgem no âmbito do próprio educativo. E aí a gente passa para aqueles trâmites de orçamento, a gente conversa com a chefia da divisão, às vezes vem alguma idéia da chefia e a gente elabora e discute, vê a viabilidade, o interesse. Mas geralmente as propostas elas saem da equipe mesmo, dos educadores. (MAE-USP - educador 2).

No processo de concepção das ações educacionais, portanto, prevalece o olhar dos educadores. São eles que determinam que ações serão direcionadas para que tipo de público. Nesse sentido é importante considerar os públicos como um fator a mais no direcionamento dessa concepção. A perspectiva educacional dialógica aparece no depoimento a seguir:

6 O setor educativo do MAE-USP é um serviço técnico da Divisão de Difusão Cultural (DDC).Além dessa o MAE-USP possui também a Divisão Científica (DC) que congrega os pesquisadores em Arqueologia e Etnologia.

$7 \mathrm{Na}$ época da realização deste trabalho (MARTINS, 20II) a Divisão Científica do MAE-USP contava com 15 docentes na ativa, e dois aposentados, além de 10 técnicos. Na Divisão de Difusão Cultural o MAE-USP contava com três docentes e quatro técnicos. 
O nosso trabalho é na provocação, o que eles estão observando, o que vem a partir desse contato, o que desperta, que assunto. Então não tem um conteúdo fechado. É a partir do que esse contato provoca, do repertório que ele já tem. É lógico que se um grupo não fala nada, não é que a gente vai ficar ali no "achismo». Mas, nosso objetivo é muito mais que essa visita, que ela acabe sendo construída pela demanda do grupo do que por uma série de conteúdos que a gente tem que cumprir. Não é isso. Não estou falando que o conteúdo não seja importante, mas que ela não pode ser o foco da visita. (MAE-USP - educador 2).

Configura-se também como um "conteúdo" essencial da educação praticada no MAE-USP o conhecimento trazido pelo público - já que a proposta do setor é que, no desenrolar das atividades, os conteúdos tratados sejam selecionados a partir do que são os seus conhecimentos prévios e expectativas temáticas em relação à ação educacional. Um aspecto que ressalta essa tendência é explicitado no depoimento da educadora transcrito a seguir:

E a nossa próxima proposta que é a elaboração de um kit pra discutir as culturas africanas também vem um pouco em perceber que não tem muito material. [...] Porque é um conteúdo que a gente começou a ter uma procura maior na visitação, para esse roteiro expositivo que era um roteiro muito pouco procurado.Agora tem disciplina, na graduação, é uma disciplina de história da África. É um conteúdo que está sendo trabalhado em sala de aula. $E$ aí os professores vêm procurando mais. (MAE-USP - educador 2).

Outro aspecto da tendência de buscar compreender as expectativas dos visitantes é por meio da promoção do diálogo entre os conteúdos dos educadores e dos públicos. Esse aspecto é explicitado a seguir, na descrição da metodologia empregada durante as visitas educativas.

Primeiro é nessa provocação sempre. Então a gente vai questionando, nesse questionamento, procurando que eles observem determinados detalhes e levantem hipóteses. E para isso você tem que ter, eu falo quando a gente está formando os estagiários, tem que ter um conhecimento muito grande daquilo que você está falando. Não é que o fato de você não priorizar o conteúdo que você não tenha que ter o conteúdo, pelo contrário, tem que dominar super bem o conteúdo para saber onde que você está querendo chegar. $E$ às vezes o olhar do público vai para um elemento, não é nem um elemento chave, um dos aspectos principais que geralmente aparecem, é uma outra coisa, só que super-interessante, você tem que pegar o gancho. Então é ficar atenta, provocando mesmo, e ficar atenta nas respostas que vêm, e ir fazendo as amarrações. (MAE-USP - educador 2).

A partir do exposto, percebe-se que na concepção do discurso instrucional do MAE-USP, o como do discurso instrucional específico, o educador8 transfere ao visitanteg uma parcela do poder decisório sobre os conteúdos e o ritmo da aquisição. Ou seja, o visitante, no processo educacional do MAE-USP, tem explicitamente um papel ativo, tanto sobre a seleção e a sequência dos conteúdos, quanto sobre seu ritmo. É a partir de seus conhecimentos prévios o que ele já sabe sobre o assunto - e sobre suas expectativas - o que ele quer saber - que são desenhadas as ações.

8 Dentro da teoria de Bernstein o educador pode ser visto como o transmissor.

9 Dentro da teoria de Bernstein o educador pode ser visto como o aquisidor. 
Os conteúdos previamente selecionados pelo educador podem, dessa forma, ser parcialmente modificados do ponto de vista de seu aprofundamento (seleção); sequência e ritmo de abordagem; e novas relações podem ser estabelecidas entre educadores e visitantes no decorrer das atividades.

É possível afirmar, portanto, que a atuação das regras discursivas - que definem o grau de controle que os transmissores e aquisidores podem ter sobre o processo de aquisição/transmissão - traduz uma educação com grau de enquadramento fraco no MAE-USP. Isso quer dizer que existem diferentes possibilidades de regulagem de transmissores e aquisidores sobre a seleção de conteúdos, sequência, ritmagem e critérios de avaliação.

Outro aspecto do discurso instrucional se dá por meio da atuação das regras de hierarquia - que dizem respeito às relações de poder entre os sujeitos transmissores e aquisidores / educadores e público visitante - na educação do MAE-USP, que produzem uma relação fracamente classificada entre os sujeitos. Ou seja, as fronteiras de demarcação entre educadores e visitantes são suavizadas, na medida em que eles podem partilhar a condução do processo educacional.

Vale ressaltar que a equipe de educação do MAE-USP não realiza avaliações sistemáticas de suas ações educacionais I0. Dessa forma todas as atividades são concebidas tendo como base a percepção, não sistemática, dos educadores sobre a reação dos públicos durante o desenrolar das atividades.

Essas características do discurso instrucional do MAE-USP o estabelecem, nos termos da teoria de Bernstein, como uma prática instrucional indireta. De acordo com Domingos e outras (1986) essa prática é caracterizada pelos seguintes elementos.

Centrada no inquérito e orientada para a descoberta e que tem as características da pedagogia invisível - o espaço é flexível, o aluno é activo, os materiais são diversificados e existe integração entre as áreas do currículo; as regras de seqüência são implícitas, a ritmagem é enfraquecida (isto é, dentro de certos limites o aluno organiza seu trabalho e segue um ritmo próprio de aprendizagem), os critérios são implícitos e a avaliação acentua as vias do conhecer (e não os estádios do conhecimento). Os alunos podem, neste caso, manejar a sua própria gramática de aquisição, sendo a modalidade de controlo do tipo pessoal. Este modelo de instrução retira as suas regras de teorias orientadas para a lógica da aquisição, que assentam sobre o desenvolvimento da criança, sobre a linguagem e sobre o comportamento (teorias de Piaget, Chomsky e da Gestalt). (Domingos et al., 1986, p. 307).

No caso do MAE-USP algumas teorias e autores da área educacional são apontados como referência para a construção do trabalho educativo. Destaca-se a citação de Paulo Freire, retomado inúmeras vezes ao longo da fala dos educadores entrevistados, bem como dos princípios denominados de construtivistas.

O que eu coloco como o conteúdo, essa mudança de atitude como o grande objetivo lá na frente. Para que isso aconteça a gente trabalha

10 A equipe educativa do MAE-USP coleta dados sobre a satisfação do público escolar na visita monitorada à exposição de longa duração. Esses dados são coletados tanto junto ao professor, por meio de uma ficha de auto-preenchimento, quanto aos alunos, por meio de uma atividade de finalização da visita. O monitor responsável pela visita também preenche uma ficha de avaliação sobre o aproveitamento do grupo visitante. Também são coletados dados de avaliação em outras atividades voltadas para os diversos públicos que participam dos cursos e atividades de formação. 
dentro dessa perspectiva construtivista. [O construtivismo é] Acho que partir dos repertórios pessoais, os contextos pessoais específicos, e a partir daí o conhecimento ir se formando.Tem muito a ver com o Paulo Freire, então as coisas vão se encaixando. (MAE-USP - educador 2).

O processo de aprendizagem, baseado no construtivismo e na pedagogia de Paulo Freire, traz elementos marcadamente dialógicos à estrutura educacional do MAE-USP, contribuindo para sua percepção como uma prática instrucional indireta, nos moldes propostos por Bernstein.

O caso da Pinacoteca do Estado de São Paulo apresenta nuances semeIhantes aquelas encontradas no MAE-USP. No que se refere à escolha do que da ação educativa, ou seja, à escolha dos temas específicos que serão abordados, o foco é estabelecido partir do acervo institucional exposto em sua mostra de longa duração e exposições temporárias. Esses acervos estão, entretanto, inseridos na lógica discursiva das exposições que conta com pouca ou nenhuma participação do Núcleo de Ação Educativa em sua concepção.

A gente sempre trabalha com a idéia de que o ato educativo, principalmente de visitas, ou de fazer um folder, é uma curadoria também. Uma curadoria educativa. É uma idéia que vem sendo tratada de forma bastante sistêmica, no sentido de pensar que quando você seleciona as obras e tece um discurso sobre elas, isso é uma curadoria. E, portanto, quando o educativo seleciona a obra $\mathrm{X}$, e pula $\mathrm{Y}$ e K, e estabelece relações entre, isso é um processo curatorial também, que tem como fundo um interesse educativo. Independente da curadoria existe uma segunda curadoria, que é uma curadoria educativa, que re-divide, seleciona as obras e reconstrói um discurso que pode ser outro. Também na visita a gente deixa claro qual é o pensamento curatorial. (PINA educador I).

A proposição da "curadoria educativa" permite aos educadores maior liberdade de ação frente aos desígnios da curadoria, expressos no discurso expositivo. $O$ foco na acessibilidade do acervo faz com que as possibilidades de leitura educativa das obras expostas sejam múltiplas.

Para o grande público, muitas vezes, a idéia do curador é invisível. [...] É muito complicado quando o curador entende a exposição como um livro, ou uma tese, uma idéia a ser depreendida, porque nem sempre isso está visível para o público, e nem sempre interessa para o público. E eu acho que toda ação precisa de respaldo político, no sentido que nos está autorizado explorar outras possibilidades de relação que não necessariamente da curadoria. [...] A gente se apropria desse discurso [da curadoria] conforme a necessidade, as possibilidades, as respostas do público ou, por exemplo, nos nossos materiais para professor, o que é o interesse pedagógico pro nível dele, por um lado, ou o que é o interesse desse público médio, espontâneo que ninguém sabe quem é. (PINA - educador I).

A fala da educadora deixa transparecer a tensão existente entre o Núcleo de Ação Educativa da Pinacoteca e a curadoria das exposições.A percepção dos educadores da Pinacoteca é a de que a educação, a princípio, não tem um espaço para além do dia-a-dia das ações propostas pelo Núcleo.

Agora a gente está em um primeiro ensaio, que é o processo de reconstrução da exposição de longa duração do acervo, que a gente pre- 
tende que seja mudada em 20I0. Desde o início desse ano eles [a equipe do Núcleo de Pesquisa e Crítica em História da Arte da Pinacoteca] começaram com uma série de atividades, primeiro de avaliação interna e avaliação do público dessa exposição. Segundo, conversas com especialistas. E o que se pretende é ano que vem criar uma equipe de reflexão para repensar essa exposição. Mas acho que já houveram alguns avanços nesse sentido. Por exemplo, a gente fez uma avaliação com os educadores e com os atendentes de sala e passamos esses resultados para a pesquisa. Está sendo feita uma pesquisa com o público para ver o que eles acham da exposição. Um dos especialistas que veio falar é a Denise Grinspum, que é uma educadora. Fizemos uma reunião dos educadores com a pessoa que está gerindo esse processo dentro do Núcleo de Pesquisa pra trocar idéias. Nós fizemos alguns ensaios de interface. (PINA - educador I).

O relato apresentado demonstra como o Núcleo de Ação Educativa vem tentando negociar a inserção do discurso educacional entre os discursos presentes na concepção de uma exposição. Esse processo, entretanto, não é simples, envolvendo, principalmente, a abertura de espaço para as necessidades dos públicos frente ao discurso especializado da curadoria. $\bigcirc$ relato a seguir traz mais elementos para a análise desse processo.

A ação educativa entra no processo de trabalho [da abertura de uma exposição], às vezes quando a exposição está pronta, às vezes não. $O$ que não significa que a gente participe do que eu acho que deveria participar, que é da construção da expografia da exposição. Muito raro a gente fazer isso. Não que já não aconteceu, mas não é uma dinâmica comum. Como coordenadora, o que eu faço? Converso com o diretor para que isso seja cada vez mais comum e que se configure em uma prática sistêmica. (PINA - educador I).

Existe, portanto, a consciência por parte da coordenação do Núcleo de Ação Educativa da Pinacoteca que sua participação nos processos decisórios de concepção e execução de uma exposição representa um maior espaço para a ampliação da missão educacional no Museu. Esse espaço, que diz respeito a possibilidades de um maior exercício de poder, representa também a possibilidade de um maior engajamento institucional naquilo que os educadores consideram que deva ser a missão pedagógica do Museu.

A existência de uma equipe coesa do ponto de vista ideológico é uma característica ressaltada pela dinâmica do trabalho em equipe. De acordo com relatos dos educadores entrevistados, existem dois caminhos para a proposição de novas ações educacionais. Um primeiro caminho é a partir daquilo que os educadores consideram importante para composição da ação educativa de um museu de artes plásticas. $O$ processo de eleição das escolhas é feito de forma compartilhada, conforme relatado pela educadora:

Como é essa lógica atualmente: cada programa tem os desafios que quer fazer, cumprir, que percebe como necessidade, que quer discutir ou quer aprofundar. Eu, da minha parte como Núcleo, também penso em algumas ações macro. Ou, por exemplo, quando um pensa em uma coisa, outro pensa em outra e outro pensa em outra, dá pra juntar isso num guarda-chuva. Um pensamento de gestão nesse sentido, de organizar que coisas podem estar associadas ou produzirem efeitos mais amplos. (PINA - educador I). 
Nesse sentido, os coordenadores dos vários programas têm autonomia de proposição de novas ações a partir daquilo que é considerado o pensamento educacional do grupo. Outra motivação para a seleção das ações que serão realizadas são as demandas do público.

[...] eu acho bem importante, pensar o nosso planejamento a partir de demandas do público. Então, por exemplo, a Galeria Tátil, que a gente está montando para cegos, é uma resposta à uma demanda de um espaço que é possível fruir autonomamente pelos cegos. Para nós isso é um desafio profissional maravilhoso. A gente também quer fazer. Mas essa vontade se conjuga com uma demanda. (PINA - educador I).

Ressalta-se que para a percepção das expectativas do público, bem como dos resultados obtidos por meio das ações educacionais, a Pinacoteca realiza avaliações sistemáticas em várias de suas ações educativas. Destaca-se, principalmente o uso da metodologia "Resultados genéricos de aprendizagem"।, desenvolvida especialmente para a aferição dos resultados educacionais em museus e outros espaços não formais de educação. Por trazer uma perspectiva mais ampliada do que são esses ganhos educacionais - não restritos, por exemplo, apenas ao aprendizado conceitual - a metodologia traz aportes para a construção de indicadores específicos para a avaliação da educação praticada nos museus. De acordo com os depoimentos dos educadores da Pinacoteca os resultados obtidos por meio desse tipo de avaliação, além de subsidiar modificações na prática educacional, permitem a negociação de mais verbas junto à direção do Museu.

A hierarquia da proposição de novas ações passa por alguns estágios antes de assumir sua forma final. O primeiro é uma discussão interna a cada programa que é, anualmente, debatida com a coordenação do Núcleo. Nesse momento é negociada, principalmente, a questão da disponibilidade de recursos humanos para os projetos que a equipe deseja executar. Caso existam projetos que a equipe deseje realizar e não haja disponibilidade de profissionais para executá-lo, inicia-se uma discussão acerca da viabilidade de novas contratações. Após serem decididos os projetos a serem executados durante o ano, a coordenação do Núcleo leva o planejamento para a direção da instituição.

E aí é uma questão de patrocínio [...], é uma coisa muito superior à gente. A gente propõe, isso é submetido à direção, a direção submete à Secretaria, então tem uma hierarquia. Alguns, a maior parte deles, precisa de subsídio financeiro, então não adianta nada falar sim e não ter verba. (PINA - educador I).

Diferentemente do MAE-USP, que recebe a maior parte dos subsídios para seus programas educacionais diretamente da Universidade, a Pinacoteca depende de patrocínios diretos ou via leis de fomento.A lógica dos eventos "patrocináveis" é, portanto, aquela que a ação educacional institucional deve se submeter.

Essa lógica institucional estabelece um foco de tensão com aqueles que são os pilares da proposição das ações educacionais da Pinacoteca. Ao mesmo tempo em que se deseja a ampliação do acesso ao acervo institucional as barreiras internas (relação com a equipe de pesquisa e curadoria) e externas (políticas de financiamento das ações) estabelecem os limites da recontextualização do

I Para a utilização dos Resultados genéricos de aprendizagem em suas atividades a equipe da Pinacoteca fez uma adaptação do projeto inglês, criando os seguintes indicadores: aquisição de conhecimento e compreensão relacionados ao conhecimento formalizado; aquisição de habilidades; mudança de valores, atitudes e sentimentos; promoção de prazer, inspiração e criatividade; e mudança de comportamento. Para maiores informações ver http://www.inspiringlearningforall.gov.uk/toolstemplates/genericlearning/. 
discurso pedagógico institucional (Martins, 2013). Nesse sentido, o conceito de educação líquida traduz as possibilidades de interação do educador com as expectativas e conhecimentos prévios do público, enfatizando de forma contundente a autonomia dos educadores na proposição de suas ações.

Então é nesse sentido que eu acredito nessa possibilidade de construir a visita, que é uma das coisas que está nesse texto que eu falo lá de um termo que é educação líquida, que vai se modelando segundo o público, um recipiente, que é uma metáfora. (PINA - educador I)

Em termos metodológicos o conceito de educação líquida traduz as múltiplas possibilidades de interpretação do acervo, cada qual adequada a uma tipologia de público. Sua estrutura centra-se no conceito da adaptabilidade do educador frente às necessidades do público. Os momentos de uma visita ao Museu são adequados a essa lógica.

A metodologia tem que ser construída a partir da resposta, é isso que é educação líquida. Como você conduz, o que você dá, a quantidade de informação e pergunta, e atividade, e apresentação institucional, e parecer pessoal, que você coloca na tua visita é em resposta ao que o público quer, não é algo pré organizado, é algo que se organiza no processo de construção. (PINA - educador I).

As possibilidades de atuação do educador nesse diálogo com os públicos pressupõem uma formação bem estabelecida, tanto de conteúdos quanto de métodos educacionais.

É difícil, mas por isso que os educadores têm que ser formados, por isso que a gente faz eles acompanharem várias coisas com educadores da casa que já tem um traquejo de fazer isso. Por isso que a gente insiste em trabalhar com eles Abigail Housen. Porque você não vai falar de movimento surrealista para uma criança de seis anos. Não tem sentido. Por isso quando a gente fala que os núcleos de articulação e de pensamento das ações da gente partem desse pressuposto de qualificar essa experiência, eu tenho que respeitar o que é essa demanda, porque se não eu estou desqualificando essa experiência, ao invés de qualificar. Por mais informação e por mais ilustrado que eu seja, isso não importa. Não é o que o outro quer receber. (PINA - educador I).

A autora Abigail Housen (I 999 apud Rossi, 2006) trabalha com o conceito de níveis de percepção/desenvolvimento estético, que podem ser desenvolvidos, em uma escala progressiva, a partir de uma interação de cunho educacional com as obras de arte2. $O$ trabalho de Housen centra-se na possibilidade de aprender a apreciar uma obra de arte, por meio da chamada "compreensão estética". Para conduzir o grupo o educador precisa, portanto, compreender em que "nível de desenvolvimento estético" ele se encontra e, dialogando com as possibilidades presentes nesse nível, conduzi-lo, se esse for seu interesse, para outros patamares de compreensão da obra. Para isso, a visita educativa da Pinacoteca é composta de três momentos: a apresentação da instituição e das regras de comportamento no espaço do Museu, a atividade de leitura da obra de arte baseada nos níveis de compreensão estética - e as propostas poéticas. Sobre as propostas poéticas o depoimento da coordenadora do Núcleo de Ação Educativa é bastante explicativo.

2 As habilidades para a compreensão estética são acumuladas à medida que o público evolui ao longo dos estágios, que são denominados de narrativo, construtivo, classificativo, interpretativo e re-criativo. 
[...] um mecanismo, não de desenvolvimento técnico, mas de desenvolvimento perceptivo e cognitivo, que é de uma outra ordem, que não necessariamente se baseia em uma aprendizagem técnica ou na realização de algo técnico em termos de arte, linguagem artística. [...] As propostas poéticas são atividades, não necessariamente produtivas no sentido de objetos, não necessariamente originam algo concreto, pode ser uma performance, pode ser um som, não importa. São dois objetivos específicos: um, dar concretude ao aprendizado cognitivo ou perceptivo, e outro, torná-lo vivencial, literalmente fazê-lo passar pelo corpo.

As propostas se constituem como uma série de atividades práticas utilizadas pelos educadores durante as visitas educativas com os grupos organizados. Elas abordam diferentes temáticas relacionadas ao universo artístico, algumas vezes em relação direta com uma obra de arte específica, outras vezes explorando temáticas do mercado da arte, ou das relações entre os artistas e seus públicos etc. Assim como o restante das atividades ela é adaptada conforme o perfil e os interesses de cada grupo visitante.

Muitos adultos não querem uma visita dialógica, e sim uma visita informativa, então eu faço uma visita informativa. Quando você já tiver conquistado a amizade desse grupo, você pode até lançar uma pergunta, mas não é o que eles vieram procurar, então não adianta você "enfiar goela abaixo" uma coisa que o público não quer.Tem uns [educadores] que fazem isso, a gente conversa. Não pode fazer uma coisa estereotípica para todos os públicos, isso não existe. A tua metodologia tem que ser construída a partir da resposta, é isso que é educação líquida. (PINA - educador I).

A partir do exposto é possível perceber que, assim como no MAE-USP, no discurso instrucional específico da Pinacoteca do Estado o educador também transfere ao visitante uma parcela do poder decisório sobre os conteúdos e o ritmo da aquisição. $O$ visitante, dessa forma, atua de forma contundente na negociação do que será visto na exposição e quanto tempo a visita durará. Suas expectativas e conhecimentos prévios, mais uma vez, atuam no desenho das ações.

O enquadramento e classificação fracas das regras discursivas e de hierarquia, a exemplo do primeiro museu analisado, traduzem-se na Pinacoteca em diferentes possibilidades para a seleção de conteúdos, sequência, ritmagem e critérios de avaliação assim como entre as fronteiras suavizadas nas relações entre educadores e visitantes. Dessa forma, as características do discurso instrucional da Pinacoteca também estabelecem uma prática instrucional indireta.

\section{Conclusão}

A busca pela compreensão da especificidade da educação em museus foi o motor que motivou a construção da investigação que embasa este artigo. Partindo da hipótese de que essa educação tem características em seu funcionamento que a diferenciam de outras modalidades educacionais, como a educação escolar, optou-se por um estudo que possibilitasse a apreensão dos seus elementos singulares. $O$ primeiro desafio a ser superado foi a diversidade de tipologias de museus e de ações realizadas pelos seus setores educativos. Como encontrar uma via analítica que permitisse olhar para essa multiplicidade de instituições, ações e sujeitos de uma maneira coesa e coerente?

A escolha pelo sociólogo da educação, Basil Bernstein, não se deu por acaso e está relacionada principalmente ao tipo de dado encontrado durante 
o processo de coleta de dados. A escolha de centrar o olhar sobre os serviços educativos dos museus trouxe a especificidade da fala do educador e essa fala revelou, principalmente, as relações sociais constituintes da educação praticada no espaço do museu. $O$ espaço da educação frente às demais funções desempenhadas pela instituição e os processos decisórios para as escolhas de forma, conteúdo e metodologia das ações.

O caso dos museus estudados é particularmente rico para a compreensão da forma como se estruturam esses processos. Salienta-se que esses museus foram escolhidos justamente pela importância adquirida pela educação em seu interior. São instituições nas quais as ações educativas, bem estruturadas por um período de mais de cinco anos, se constituem, além de tudo, como referência para a área de educação em museus nacional. Se o panorama encontrado não permite generalizações imediatas para outras instituições museais, ele permite, por outro lado, inferir sobre o processo contemporâneo de estruturação da área educacional em museus no Brasil. Ao mesmo tempo, os "casos exemplares", depreendidos a partir de uma metodologia qualitativa de estudos em Educação, trazem à luz os caminhos institucionais percorridos pelos profissionais da área na estruturação do setor educativo dos museus. Considera-se que esses caminhos, à parte as singularidade contextuais, são elementos da especificidade dos processos de educação em museus.

O conceito de dispositivo pedagógico proposto por Bernstein permite, justamente, a apreensão desses processos constitutivos. É possível compreender, por exemplo, quais aspectos delimitam a inserção da educação nos museus estudados.

O que se deduz dos casos analisados é que, apesar das transformações históricas ocorridas sobre a função educacional dos museus no último século (Abt, 2006; Schaer, 1993), sua inserção institucional ainda é alvo de controvérsias. A compreensão de como os relacionamentos com os públicos - paradigma de atuação museal da contemporaneidade - deve ser estruturado não é igual para todos os profissionais de museus, e não passa necessariamente, na visão de muitos deles, pela atuação dos setores educativos. Essa afirmação é particularmente emblemática no caso da Pinacoteca, onde o discurso expositivo é a principal via de comunicação do Museu com os seus públicos e em cuja concepção os educadores muitas vezes não têm voz. No MAE-USP essa voz existe, mas a educação encontra outras barreiras internas, advindas da relação hierárquica entre a área de educação e a área científica no interior da estrutura universitária.

O posicionamento dos educadores na cadeia operatória museológica das instituições ao mesmo tempo em que coloca a educação em luta por espaços de poder com as demais funções museais, traz a possibilidade de autonomia de seus agentes. Essa autonomia é expressa pela proposição de ações que ideologicamente trazem a perspectiva de consolidação da função educacional desses museus.

O que é mais importante considerar, entretanto, é que o panorama apresentado traz a possibilidade de serem os educadores de museus os responsáveis tanto pela produção quanto pela recontextualização dos textos pedagógicos. Essa possibilidade é corroborada não só pelos diversos aspectos que compõem a sua prática profissional no interior das instituições museais mas, principalmente, por um panorama de crescimento do campo intelectual da educação em museus (Martins, 20I I; Seibel-Machado, 2008). Nesse sentido, as regras de recontextualização, no âmbito da educação em museus, colocam nos agentes museais um grande poder decisório sobre o como e o que serão reproduzidos para os públicos dos museus, em termos de discurso pedagógico.

Dentro da concepção de funcionamento do discurso pedagógico de 
Bernstein, as regras de realização atuam na estruturação do discurso instrucional específico. Como dito inicialmente, o discurso instrucional específico diz respeito ao que e ao como do processo de transmissão e aquisição. Tanto na Pinacoteca quanto no MAE-USP o foco do conteúdo do processo educacional é o acervo institucional.

No MAE-USP a escolha dos temas das ações educacionais está centrada na pesquisa em Arqueologia e Etnologia realizada pela instituição, priorizando o contato qualificado com os objetos das coleções. O objetivo é prover para os públicos uma maior percepção da diversidade cultural existente nas sociedades humanas. Sua atuação pedagógica tem raízes na metodologia da Educação Patrimonial (Horta et al., 1999) e por conta disso tem nos objetos do acervo institucional a base de seu discurso conceitual. É importante ressaltar que as ações têm uma estreita vinculação conceitual com os discursos expositivos que, por sua vez, estão baseados nas pesquisas em Arqueologia e Etnologia realizada pelos pesquisadores da instituição.

Na Pinacoteca do Estado o acervo também é prioritário. Do ponto de vista do Núcleo de Ação Educativa a promoção do acesso às coleções é a prioridade institucional. Esse acesso, entretanto, não é simplesmente físico, e sim conceitual, na medida em que se considera a necessidade de modificação do olhar e da percepção do público sobre os objetos expostos. Para isso os visitantes devem aprender determinados conceitos relacionados ao universo das artes plásticas, de forma a adquirirem autonomia em relação à "leitura de imagem" (Rossi, 2003), perspectiva de atuação que, juntamente com as "propostas poéticas", formam a base metodológica das ações educativas desse Museu. Diferentemente do MAE-USP os educadores da Pinacoteca estabelecem propostas alternativas a dos curadores das exposições, sempre que julgam necessário à compreensão do público.

A partir das análises empreendidas percebeu-se que a prática instrucional dos museus estudados traz característica de uma prática instrucional indireta nos moldes propostos por Bernstein. As estratégias didáticas utilizados pelos educadores são maleáveis conforme as características dos públicos e, nesse sentido, elas trazem a possibilidade de uma maior interação entre adquirentes/ públicos e transmissores/educadores. $O$ viés dialógico, segundo seus educadores, é adotado pelos museus estudados como a perspectiva mais adequada no trabalho com os visitantes, o que também contribui para essa maleabilidade no posicionamento dos sujeitos.

Mais uma vez o que se destaca é a autonomia propositiva dos educadores, principalmente no que se refere às metodologias empregadas nas ações. Quanto aos conteúdos conceituais existem diferentes graus de possibilidades alternativas aos discursos dos curadores/pesquisadores das coleções/conteúdos específicos - de uma aparente maior regulação no MAE-USP a uma certa "independência" da Pinacoteca.

É importante ressaltar, entretanto, que em ambos os casos existem processos de regulação internas e externas à proposição das ações, não abordadas nesta artigo, como as formas de financiamento (Martins, 20 I3), quanto na estrutura interna de decisões institucionais na qual os educadores se encontram inseridos. A existente autonomia dos educadores na proposição conceitual e metodológica das ações está, portanto, estabelecida a partir dessas condicionantes. 


\section{Referências}

$A B T$, J. The origins of the public museum. In: MACDONALD, S. A companion to museum studies. Carlton (Australia): Blackwell, p. I I5-I34, 2006.

ALLARD, M.; BOUCHER, S. Le musée et l'école. Montréal: Hurtubise HMH, 199I. BERNSTEIN, B. A estruturação do discurso pedagógico. Classe, códigos e controle. Petrópolis:Vozes, 1996. . Pedagogía, control simbólico e identidad. Madrid: Morata, Paideia, 1998.

BOGDAN, R.; BIKLEN, S. Investigação qualitativa em educação. Porto: Porto Editora, 1994.

BRUNO, M. C. O. Musealização da arqueologia: um estudo de modelos para o Projeto Paranapanema. 1995. Tese (Doutorado) - Museu de Arqueologia e Etnologia, Universidade de São Paulo, São Paulo, 1995.

CARNEIRO, C. G. Ações educacionais no contexto da Arqueologia preventiva: uma proposta para a Amazônia. 2009. Tese (Doutorado) - Museu de Arqueologia e Etnologia, Universidade de São Paulo, São Paulo, 2009.

COHEN, L.; MANION, L.; MORRISON, K. Research methods in education. New York: Routledge, 2007.

DOMINGOS, A. M. et al. A teoria de Bernstein em sociologia da educação. Lisboa: Fundação Calouste Gulbenkian, 1986.

FALCÃO, D.; GILBERT, J.: Método da lembrança estimulada: uma ferramenta de investigação sobre aprendizagem em museus de ciências. História, Ciências, Saúde - Manguinhos, v. I2 (suplemento), p. 93-I I 5, 2005.

FALK, J. H.; DIERKING, L. D. Learning from Museums.Visitor experiences and the making of meaning. Walnut Creek, Califórnia:Altamira Press, 2000.

. Lessons Without Limit - how free-choice learning is transforming education. Califórnia:Altamira Press, 2002.

FALK, J; STORKSDIECK, M. Learning science from museums. História, ciências, saúde - Manguinhos, v. I 2. Rio de Janeiro: Fundação Casa de Oswaldo Cruz, p. I I 7 I44, 2005.

GARCIA,V.A. R. O processo de aprendizagem no Zoológico de Sorocaba: análise da atividade educativa visita orientada a partir dos objetos biológicos. 2006. Dissertação (Mestrado) - Faculdade de Educação, Universidade de São Paulo, São Paulo, 2006.

HEIN, G. Learning in the museums. London: Routledge, 1998.

HOOPER-GREENHILL, E. Education, communication and interpretation: towards a critical pedagogy in museums. In: The educational role of the museum. London: Routledge, p. 3-25, 1994.

HORTA, M. L. P. et al. Guia Básico de Educação Patrimonial. Brasília: Instituto do Patrimônio Histórico e Artístico Nacional/ Museu Imperial, 1999.

LAROUCHE, M., ALLARD, M. Modele théorique d'évaluation à l'école et au musée: implications pour la pratique muséale. In: ALLARD, M.; LEFEBVRE, B. (Ed.). Le musée, un lieu éducatif. Montréal: Musée d’Art Contemporain de Montréal, p. 362-376, 1997. 
MARANDINO, M. O conhecimento biológico nos museus de ciências: análise do processo de construção do discurso expositivo. 200I. Tese (Doutorado) Faculdade de Educação, Universidade de São Paulo, São Paulo, 2001.

MARTINS, L. C. A relação museu/escola: teoria e prática educacionais nas visitas escolares ao Museu de Zoologia da USP. 2006. Dissertação (Mestrado) Faculdade de Educação, Universidade de São Paulo, São Paulo, 2006.

. A constituição da educação em museus: o funcionamento do dispositivo pedagógico museal por meio de um estudo comparativo entre museus de artes plásticas, ciências humanas e ciência e tecnologia. 20l I. Tese (Doutorado) Faculdade de Educação, Universidade de São Paulo, São Paulo, 201 I.

MARTINS, L. C.; MARANDINO, M. Políticas de financiamento da educação em museus: a constituição das ações educacionais em museus de artes plásticas, ciências humanas e ciência e tecnologia. Ensino Em Re-Vista, v.20, n.I, p.57-68, jan./jun. 2013

McMANUS, P. Investigation of Exhibition Team Behaviors and the Influences on Them: Towards Ensuring that Planned Interpretations Come to Fruition. In DUFRESNE-TASSÉ, C. Cultural Diversity, Distance and Learning. Quebéc: ICOM CECA, 2000.

NAVAS, A. M. Concepções de popularização da ciência e da tecnologia no discurso político: impactos nos museus de ciências. 2008. Dissertação (Mestrado) - Faculdade de Educação, Universidade de São Paulo, São Paulo, 2008.

ROSSI, M. H.W. Leitura e releitura: estabelecendo relações. Pátio - Revista Pedagógica, Porto Alegre, v. 27, p. 50-53, 2003.

SCHAER, R. L'invention des musées. Paris : Gallimard, 1993.

SEIBEL-MACHADO, M.I.O papel do setor educativo nos museus: análise da literatura ( 1987 a 2006) e a experiência do Museu da Vida. Campinas, 2009.Tese (Doutorado) - Instituto de Geociências, Universidade Estadual de Campinas, 2009.

VAN-PRÄET, M.; POUCET, B. Les musées, lieux de contre-éducation et de partenariat avec l'école. Éducation \& Pédagogies, n. $16,1992$.

Artigo recebido em junho de 20/4.Aprovado em agosto de 20/4 
68

느

ษั

胥

ํํํ

$\stackrel{\circ}{\square}$

궁

띨

곡

茫

守

余

3

$\mathbb{5}$

욱

究 